\author{
생태관광지 방문객의 동기 및 태도에 따른 시장세분화 \\ - 경기도 대부 해솔길 방문객을 중심으로 - \\ 정윤정 · 김성일 \\ 서울대학교 산림과학부
}

\title{
Ecotourism Visitors' Motivation/Attitude-Based Market Segmentation - Focused on Visitors at the Daebu Haesolgil, Gyeonggi Province -
}

\author{
Jeong, Yoonjeong $\cdot$ Kim, Seong-il \\ Dept. of Forest Sciences, College of Agriculture and Life Sciences, Seoul National University
}

\begin{abstract}
To increase knowledge regarding the ecotourism market in Korea, this study conducted a market segmentation based on tourists' motivations and attitudes. An onsite survey of visitors to Daebu Haesol 1 gil, Gyeonggi Province, was conducted from late November 2016 to early January 2017. An exploratory factor analysis and K-means cluster analysis were employed to identify market segments by using data collected from 434 respondents. The results showed three distinct segments labelled 'Nature Seeking Responsible Tourists', 'Passive Nature Seeking Tourists' and 'Nature/Cohesion Seeking Responsible Tourists.' All three segments had different levels of 'escape', 'health' and 'cohesion' motivations but commonly they all had a relatively high level of 'nature' motivation. As they also differed from each other in terms of sociodemographic and travel related characteristics as well as satisfaction level, it was concluded that motivation and attitudes of responsibility can be used for ecotourism market segmentation. A significant implication is that this research confirmed that the indicators on tourists' attitude of responsibility toward local communities are useful in segmenting visitors to ecotourism sites, which have been rarely studied in previous ecotourism market studies.
\end{abstract}

Key Words: Sustainable Tourism, Tourist Database, Visitor Management, K-means Cluster Analysis

\section{국문초록}

이 연구는 우리나라 생태관광지 방문객 시장에 대한 이해를 높이기 위하여 우리나라 생태관광지를 방문하는 국내 관광객의 생태관광 동기와 태도를 바탕으로 시장세분화를 실시하였다. 2016년 11월 말부터 2017년 1월 초까지 경기도 대부 해솔 1 길을 방문하는 관광객을 대상으로 설문조사를 실시하여 수집된 434명의 응답자료를 분석에 이용하였다. 탐색적 요인분석과 K-means 군집분석을 이용하여 방문객의 동기와 태도를 바탕으로 시장을 세분화하였다. 그 결과,

${ }^{+}:$이 연구는 서울대학교 농업생명과학연구원 및 경기관광공사의 지원을 받아 수행되었음.

Corresponding author: Seong-il Kim, Dept. of Forest Sciences, College of Agriculture and Life Sciences, Seoul National University, Seoul 08826, Korea, Tel.: +82-2-880-4765, E-mail: seongil@snu.ac.kr 
방문객들을 ‘자연탐방형 책임있는 관광객', ‘소극적 자연탐방형 관광객' 그리고 ‘자연탐방 및 친목도모형 책임있는 관광객' 으로 분류할 수 있었으며, 세 개의 세분시장은 공통적으로 ‘자연탐방' 동기가 두드러졌으나, 각기 다른 수준의 '일상탈출', '건강증진', ‘친목도모' 동기와 생태관광 태도를 갖는 것으로 나타났다. 또한, 각 세분시장 간에는 인구통계적 특성, 여행 특성, 만족도에서 통계적으로 유의미한 차이를 보이는 것으로 나타나, 이 연구에서 사용된 생태관광 동기와 태도 척도가 생태관광지 방문객 시장을 세분화하는 기준으로 유용하다는 것을 확인하였다. 과거 연구들이 관광객의 환경관련 태도만 측정하여 시장세분화 가능성을 확인한 반면, 이 연구는 지역사회 및 주민에 대한 책임 있는 행동에 대한 태도의 측정과 분석을 포함하고 있다는 점에서 보다 포괄적이고 생태관광지에 특화된 기준으로 시장 세분화의 가능성을 확인했다는데 의의가 있다.

주제어: 지속가능한 관광, 관광객 데이터베이스, 방문자 관리, K-means 군집분석

\section{I. 서론}

한국은행의 발표에 따르면 우리 국민의 해외여행 지출은 2017년 270억 달러로 2016년에 이어 또 한 번 사상 최대치를 기록했다. 우리나라의 해외여행객 수는 꾸준히 증가해 왔으며, 2018년 1월에는 내국인 출국자 수가 역대 최대 규모인 286만 명에 달했다. 최근 $3 \%$ 대로 올라선 경제 성장률과 수출 활황에 따른 원화 강세에 힘입어 해외로 떠나는 여행객 수의 증가세는 지속될 것으로 보인다. 그에 반해 국내 관광은 외래 입국자 수 가 2017년 기준 전년 대비 $22.7 \%$ 감소하고(Korea Tourism Organization, 2018), 내국인의 국내여행 이동 총량1)이 2016년 기준 전년 대비 $1.3 \%$ 소폭 증가에 그쳐(Korea Culture and Tourism Institute, 2017) 지역 활성화를 희망하는 지역민과 정 부의 기대에 미치지 못하는 상황이다. 여전히 대중관광의 틀을 벗어나지 못하고 있는 국내 관광산업도 문제점으로 지적되어 왔다( $\mathrm{Kim}, 2017 \mathrm{~b})$.

일찍이 90년대 초부터 선진국들은 대중관광의 사회적, 경제 적, 환경적 문제들을 최소화시키면서 질적인 경험을 제공하는 대안관광에 대한 관심을 가져왔다. 특히 대안관광 중 하나인 생태관광은 '자연보전', '지역주민 참여 및 복지향상', '체험교육' 의 3 가지 기본 개념을 포함하는 관광으로(TIES, 2015), 지역의 우수한 자연 - 문화를 보전해 특색 있는 프로그램과 컨텐츠를 개발하고, 고부가가치를 창출하여 대중관광의 문제를 해결하는 적절한 대안으로 꼽힌다. UNEP(the United Nations Environmental Program) 과 UNWTO(the United Nations World Tourism Organization)는 자연, 유산, 문화, 모험 등과 관련된 관광이 향후 20여 년 동안 급속하게 증가할 것이며, 특히 생태 관광에 대한 세계적인 지출이 다른 어느 관광보다도 높은 증가 율을 보일 것이라고 예측했다(UNEP and UNWTO, 2012). 생 태관광이 전국에 활성화되면 굳이 해외여행을 떠나거나 외국 인들에게 우리나라를 찾아 달라고 조르지 않아도 여행 적자가 자연스럽게 해결되며, 관광산업의 최대 약점인 외국에 종속되 는 관행에서 벗어날 수 있을 것이다.
우리나라는 2008년 환경부와 문화체육관광부가 공동으로 '생태관광 활성화 방안'을 수립하고, 생태관광 공급 확대 정책 을 시행해왔다. 환경부는 생태관광을 습지보호지역, 생태·경 관보전지역 등 '생태계가 특히 우수하거나 자연경관이 수려한 지역에서 자연자산의 보전 및 현명한 이용을 통하여 환경의 중요성을 체험할 수 있는 자연친화적인 관광 ')으로 정의하고, 2010년부터 생태관광 모델사업과 시범사업을 시행하였다. 2013 년에는 자연환경보전법을 개정하여 생태관광 활성화를 위한 생태관광지역 지정 제도를 도입 및 시행하였다. 이에 생태관광 지역 지정을 원하는 많은 지방자치단체와 지역주민들이 지원 하였으며, 2018년 5월 현재 평가 기준을 통과한 전국 26개의 지 역이 생태관광지역으로 지정되어있다. 이 외에도 문화체육관 광부와 한국관광공사가 2009년부터 2015년까지 '한국 슬로우시 티 육성' 등의 도시단위 생태관광 사업을 한국관광공사와 함께 지원하였다. 2016년부터는 해당 사업을 '생태테마관광 공모사 업’으로 전환하였으며, 2018년 최근에는 생태관광에 인문학 테 마를 담은 14 건의 생태테마관광 사업을 선정하였다. 생태관광 지역 지정을 원하는 지방자치단체 및 지역은 꾸준히 증가하고 있어 생태관광 공급은 더욱 확대될 것으로 보인다.

그러나 우리나라의 생태관광 자원 공급 확대에 비해 생태관 광 시장에 대한 연구는 미흡하다. 생태관광 개발이 공급자적 측면에만 편중될 경우, 수요자의 요구를 충분히 반영하지 못하 는 문제가 발생한다. 따라서 생태관광 개발 시 시장에 대한 충 분한 조사연구를 통해 시장수요를 폭넓게 반영하는 것이 필 요하다(Kim, 2002). 비록 우리나라에서는 1992년 한국관광공사 의 '국민여행실태조사'를 시작으로 2018년 현재까지') 매년 국 민들의 전반적인 여행 목적, 여행 지출액, 여행 소감 등을 조 사하고 있으나, 생태관광지 방문객을 대상으로 관광지의 자연 환경 및 지역사회 등에 대한 책임 있는 태도나 행동관련 질문 을 포함하는 특화된 설문조사 사례는 찾아보기 힘들다. 또한, 일부 생태관광지역에서 자체적으로 방문객을 대상으로 생태관 광지 방문 만족도 또는 프로그램 참여 만족도를 조사하고 있으 나, 그 내용이 단순하여 설문조사 결과를 활용한 관광객 마케 
팅이나 관광지 관리 전략을 마련하기에는 한계점이 있다.

이미 일부 선진국에서는 생태관광지를 방문하는 관광객의 인 구 통계적 특성, 여행 특성, 방문 동기 등에 대한 자료를 수집 하여 데이터베이스를 구축한다. 또한, 이를 바탕으로 관광지 별 마케팅 전략을 수립하고, 그 내용을 담은 보고서를 정기적 으로 발간한다(Northest Michigan Council of Governments, 2012; Shouf Biosphere Resever, 2009; Queensland Government 2013). 이러한 활동의 주요 목적은 생태관광지를 방문하는 관 광객의 동기를 잘 파악하고, 그 기대에 상응하는 품질의 관광 상품을 제공하여 관광객의 만족을 이끌어내는 것이다. 뿐만 아니라, 생태관광은 대중관광과 달리 자연환경을 보전하고 지 역에 경제적 이득이 돌아가도록 하는 것이 강조되는 관광이므 로, 방문객의 책임 있는 태도와 행동이 요구된다(Kang et al., 2002). 따라서 생태관광지 경영자는 생태관광지를 방문하는 관 광객의 자연환경 및 지역주민에 대한 태도를 파악하고, 이를 바탕으로 세분시장별 방문자관리 전략을 세우거나, 관광지의 지속가능한 관리에 도움을 줄 것으로 예상되는 특정 관광객 시 장을 집중 공략하는 표적 마케팅 전략을 수립하는 것이 필요하 다(Cvelbar et al., 2017).

이 연구는 우리나라 생태관광지를 방문하는 국내 관광객의 생태관광 동기와 태도를 조사, 분석하여 관광객 그룹을 세분 화하고, 이를 바탕으로 생태관광지 마케팅 및 관리 전략 마련 방안을 제시하고자 한다. 연구 목적을 달성하기 위하여 첫째, 우리나라 생태관광지를 방문하는 국내 관광객의 생태관광 동 기와 태도를 파악하고, 둘째, 이를 바탕으로 생태관광지 방문 관광객 시장을 세분화하며, 셋째, 각 세분시장의 인구통계적 특 성, 관광활동 특성, 만족도의 차이를 통계적으로 비교분석하여 넷째, 세분시장별 마케팅 전략 마련을 위한 과학적 근거를 제 시한다.

이 연구의 학술적 기대효과는 첫째, 현재까지 국내에서 큰 관심을 받지 못했던 생태관광지역 방문객에 특화된 설문조사 및 분석 방법론 개발에 기여하며, 둘째, 생태관광 동기와 태도 를 바탕으로 하는 시장세분화를 통한 표적 마케팅 가능성을 검 토하는 것이다.

\section{II. 연구사 고찰}

\section{1. 시장세분화 개념}

시장세분화(market segmentation)는 이질적인 고객으로 구 성된 시장을 동질적인 고객으로 구성된 다수의 하위 시장으로 세분하는 것을 의미한다(Smith, 1956). 이때의 동질적인 고객 으로 구성된 하위 시장을 '세분시장'이라고 하는데, 각 세분시 장 내 고객들은 공통된 인구통계적 특성이나 행동 특성, 또는
동기 및 태도와 같은 심리학적 특성을 갖고 있음을 뜻한다 (Kotler et al., 2006). 관광학에서는 관광객의 나이, 성별, 결혼 유무, 자녀의 수, 교육수준, 사회적 지위, 가구소득 등과 같은 인구통계적 특성(Diamantopoulos et al., 2003)이나 관광지에서 의 행동 특성(Cvelbar et al., 2017), 또는 동기 및 태도와 같은 심리학적 특성(Kollmuss and Agyeman, 2002)을 바탕으로 세 분시장을 정의하는 연구가 진행되어 왔다. 이 중 관광 동기와 태도는 관광객 행동을 이해하는데 유용한 도구로써 관광시장 을 세분화하는데 적합한 것으로 밝혀졌다(Park et al., 2010).

\section{2. 관광동기 관련 선행연구}

동기는 인간이 어떤 행동을 일으키게 하는 내적 요인으로 관광동기는 관광객의 행동에 영향을 미치는 요인을 의미한다 (Park et al., 2010). 즉, 관광동기는 잠재 관광객의 의사결정과 정에 영향을 미치며, 관광객이 특정 관광지에 왜 방문하는가 에 대한 이유를 알려준다(Kim and Baum, 2007). 따라서 관광 지 경영자 및 마케터는 방문객의 관광동기를 이해함으로써 그 들의 동기를 충족시켜줄 수 있는 관광 상품과 서비스를 제공 하여 방문자관리의 목표를 달성할 수 있다(Kim and Kang, 2002).

이러한 이유로 많은 연구자들이 실증적 연구를 통해 다양 한 관광동기를 목록화하고 분류하는데 노력을 기울여왔는데, Matheson et al.(2014)은 과거 실증 연구들의 결과를 분석하여 대부분의 연구에서 등장하는 관광동기가 다음의 주제를 가진 다고 하였다; 문화 탐험(cultural exploration), 가족 간의 친목 도모(family togetherness), 교제 활동(socialization), 일상에서 의 도피 및 균형 회복(escape/equilibrium recovery), 즐거움 (excitement), 진귀함(novelty)의 추구 등. 생태관광지를 방문하 는 관광객의 동기를 실증적으로 규명하고자 했던 연구에서는 일상탈출(escape), 친목도모(cohesion), 건강증진 활동(healthy activity), 자연탐방(learn about nature) 추구 등의 동기가 분 류되었다(Hultman et al., 2015; Kim and Baum, 2007; Palacio, 1997).

국내에서는 1990 2000년대 초반 생태관광지 방문객 또는 생태관광 프로그램 체험객의 동기를 파악하기 위한 실증 연구 (Kang, 1999)와 이들의 동기를 파악하고 이를 바탕으로 생태 관광지 시장을 세분화하는 연구(Park and Yang, 2006; Oh and Lee, 2008) 가 진행되었다. 그러나 환경부의 생태관광지역 지정 제도 실시 이후 최근 우리나라 생태관광지 방문객의 동기를 규 명하거나 이를 근거로 시장을 세분화하는 연구사례는 찾아보 기는 힘들다. 과거와 비교하여 생태관광지역과 프로그램 공급 이 확대되었으나, 수요자 측면을 이해하고자 하는 연구는 부족 하다. 우수한 생태관광 자원이 있더라도 관광객에 대한 충분한 이해와 이를 바탕으로 하는 적합한 마케팅 및 경영 전략이 수 
반되지 않는다면 해당 생태관광지의 지속적인 발전을 기대하 기는 어렵다. 따라서 이 연구에서는 우리나라 생태관광지를 방 문하는 관광객의 기본적인 특징과 동기를 파악하고, 이를 바탕 으로 관광객 시장을 세분화하여 마케팅 전략 수립 방안을 제시 하였다.

\section{3. 관광객 태도 관련 선행연구}

태도는 사람의 행동을 예측하는 하나의 요인으로, 사람이나 사물, 서비스, 주제, 개념 등의 특정한 지각 대상에 대한 모든 판단적 신념을 일컫는다(Ajzen, 2005). 특히 생태관광지 경영 자 및 마케터는 관광객의 태도에 대한 이해를 바탕으로 지속 가능한 관광지 관리의 부담을 덜 수 있는데, 현재까지 많은 연 구자들이 환경보전에 관심이 있거나, 친환경 태도가 높은 세분 시장을 관광지로 유도하는 '표적 마케팅(target marketing)'의 가 능성을 제시해왔다(Cvelbar et al., 2017; Dolnicar and Leisch, 2008; Formica and Uysal, 2001). Formica and Uysal(2001)은 버지니아주 방문객의 $\mathrm{NEP}(\mathrm{New}$ Environmental Paradigm) 점 수를 근거로 세 개의 세분시장 -'Conservationists', 'Anthropocentric', 'Optimists'- 을 분류하고, 각 세분시장 간의 인구통 계적 특성과 여행 특성의 통계적 차이를 밝혀 표적시장 선정을 위한 과학적 근거를 제공하였다. 그러나 이 연구는 응답자의 전반적인 환경관련 태도만을 측정하고 있다는 한계가 있는데 (Formica and Uysal, 2001), NEP와 같은 전반적인 친환경적 태도나 행동이 관광지에서도 적용되기를 기대하기는 어렵기 때 문이다(Juvan and Dolnicar, 2014).

이러한 문제점을 인식한 Dolnicar and Leisch(2008)와 Cvelbar et al.(2017)은 관광지에서 이루어지는 친환경적 태도나 행동 에 초점을 맞춘 시장세분화 연구를 진행하였다. Dolnicar and Leisch(2008)는 호주 국민을 대상으로 일상뿐만 아니라, 관광 지에서의 친환경적 태도와 행동을 조사분석하여 세분시장을 구분하고, 친환경적 태도 및 행동 점수가 높은 세분시장을 표 적으로 하는 관광 마케팅 방안을 제시하였다. Cvelbar et al. (2017)은 관광지(숙박시설)에서 이루어지는 친환경적 행동을 측정하기 위해 호텔투숙객의 타월 재사용률을 측정하였고, 타 월 재사용률이 높은 세분시장을 표적으로 하는 마케팅 전략을 제시하였다.

이들 연구는 모두 관광지에서의 친환경적 태도나 행동을 측 정하고, 이를 바탕으로 시장을 세분화했다는데 의의가 있다. 그 러나 생태관광의 지속가능성에는 단순히 자연보전만이 고려되 는 것이 아니라, 지역주민에 대한 관광객의 책임 있는 태도와 행동이 요구된다(Kang et al., 2002). 따라서 이 연구에서는 관 광지에서의 친환경적 태도뿐만 아니라, 지역주민에 대한 책임 있는 태도를 조사하고, 이를 바탕으로 관광객 시장을 세분화했 으며, 과거 연구결과와 비교해 이 연구의 구체적인 시사점을
도출했다.

\section{III. 연구방법}

\section{1. 조사설계 및 자료수집}

이 연구를 위한 조사는 2016년 11월 17일, 11월 19일, 12월 27일, 12월 28일, 12월 29일, 2017년 1월 2일, 1월 7일 총 7일 간 경기도 안산시에 위치한 대부 해솔1길 ${ }^{4)}$ 을 방문하는 15 세 이상의 관광객을 대상으로 이루어졌다. 해솔1길은 2014년 환 경부로부터 생태관광지역으로 지정된 '안산 대부도, 대송습지' 의 대표 명소이다. 해솔1길은 해안선을 따라 대부도 전체를 둘 러볼 수 있는 총 7개 코스로 구성된 '대부 해솔길(2012년 10월 개통)'의 제1코스에 해당하며, 시화방조제에서 대부도로 진 입하는 관문에 위치한 대부관광 안내소에서 시작하여 구봉도 (바다소리 해안 둘레길)를 지나 돈지섬안길까지 이어지는 약 $11 \mathrm{~km}$ 의 산책로로 이루어진다(Figure 1 참조). 산책로 구간의 대부분이 자연녹지지역으로 지정되어 있어 관광객은 우수한 자연환경과 경관을 즐기며 걸을 수 있다. 산책로 중에서도 구 봉도의 바다소리 해안둘레길(약 $3 \mathrm{~km})$ 은 해솔 1 길의 핵심 구간 으로, 종현어촌체험마을, 선돌바위 전망대, 낙조전망대 등을 포 함하고 있어 서해안의 갯벌을 체험하고 낙조를 감상할 수 있다. 조개 캐기 등을 직접 체험해 볼 수 있는 갯벌 체험 프로그램은 구봉도 마을주민들로 구성된 ‘종현어촌계’에서 운영하는 ‘종현 어촌체험마을'에서 진행하며, 해당 시설은 바다소리 해안 둘레 길 출입구에 위치한다. 마을주민들은 '종현어촌체험마을’을 통 해 갯벌체험 외에도 특산품 판매, 체험민박 운영 등의 사업에 참여하고 있다. 해솔1길에는 2015년 11월 2016년 9월 동안 약 419,812명 (구봉도 공영주차장 227,740 명, 종현어촌마을입구 $192,072$ 명 집계 $)^{5)}$ 이 방문했다.

대부생태관광주민협의체 및 종현어촌마을 관계자의 자문과 현장 답사를 통해 관광객들의 주요 동선을 파악한 후 최종적으

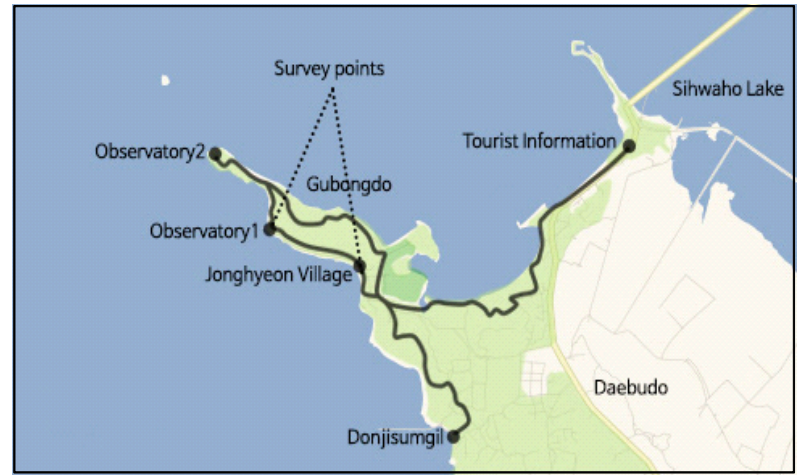

Figure 1. Daebu Haesol 1gil (route map)

Legend: Natural green area Green area for conservation 
로 해솔1길 선돌바위 전망대 및 종현어촌체험마을이 위치한 출 입구 부근을 설문조사 지점으로 선정하였다. 조사기간 동안 오 전 9시부터 오후 6시까지 설문조사를 실시하였다. 설문조사는 조사원으로 섭외된 5 명의 대학생 및 대학원 석박사과정생이 사전교육을 받은 후 진행하였다. 표본추출방법은 편의표본추 출방법으로, 조사원이 해당 지점을 지나는 모든 방문객을 대상 으로 설문조사에 응해줄 것을 요청하고, 이에 동의하는 관광객 에 한하여 설문조사를 실시하였다. 설문조사로 총 434 개의 유 효 표본을 확보하였다.

\section{2. 설문조사 항목}

이 연구의 설문조사 항목은 생태관광 동기, 생태관광 태도, 여행 특성, 만족도, 인구통계적 특성으로 구성되어 있으며, 각 각의 변수는 기존의 관련 선행연구 및 보고서를 근거로 하고 있다. 먼저 생태관광 동기는 Hultman et al.(2015); Kim and Baum(2007); Palacio(1997)의 연구를 토대로 일상탈출, 친목 도모, 건강증진 활동, 자연탐방의 네 가지 동기를 구분하고 Palacio(1997)의 연구에서 사용된 동기 문항을 세부문항으로 구 성하였다(Table 1 참조). 생태관광 태도는 Kang(1999)와 Kang and Moscardo(2006)의 연구에서 사용된 문항을 추출하여 사용 하였다(Table 2 참조). 여행 특성의 조사항목은 '최근 3 년간 대 상지 재방문 여부', '체류시간, '동반자 현황(동반자 수, 유형)', '주요 교통수단', '(대부 해솔1길에서의) 지출금액'으로 구성하 였는데, 각각의 세부 문항은 한국문화관광연구원(2015a, 2015b, 2016)의 '국민여행실태조사'와 '외래관광객실태조사'에 사용된
문항을 일부 수정하여 구성하였다. 만족도의 조사항목은 "자연 및 문화 보전', ‘지리적 접근성 및 교통의 편리성', ‘지역 주민 및 직원 응대 서비스', '편의시설 관리상태', '종합 만족도', '재 방문 의향', '타인 추천 의향'으로 구성하였다. 각각의 세부 문 항은 환경부(2014)의 '지역주민 및 방문객 만족도 조사'에 사용 된 문항을 일부 수정하여 구성하였다. 응답자의 인구통계적 특 성은 ‘성별', ‘연령', ‘결혼여부', ‘거주지’, ‘최종학력', ‘직업’, ‘월 가구소득'의 항목으로 구성하였으며, 한국문화관광연구원(2015a, 2015b, 2016)의 '국민여행실태조사'와 '외래관광객실태조사'에 사용된 문항을 일부 수정하여 세부 문항을 구성하였다. 생태관 광 동기, 태도, 만족도 문항은 선행연구에 근거하여 리커트 5점 척도로 측정하였으며, 설문 항목의 번역상의 오류 및 문항의 배치 등은 전문가의 검토를 거쳐 최종 수정되었다.

\section{3. 자료분석}

설문조사로 얻은 표본을 분석하기 위해 IBM SPSS Statistics 23 통계패키지를 이용하였다. 가장 먼저 표본의 일반적 특성을 파악하기 위해 빈도분석을 실시하였다. 다음으로는 생태관광 동기 측정변수들의 타당성 및 신뢰성을 확보하기 위해 탐색적 요인분석과 신뢰도 분석(Cronbach's a)을 실시하였으며, 타당 성과 신뢰도가 확보된 생태관광 동기 변수와 태도 변수를 바탕 으로 군집분석을 실시하였다. 군집분석은 분석대상의 유사한 특 성에 기초해서 집단을 몇 개의 세부 군집으로 분류하는 분석기 법으로 마케팅을 위한 시장세분화에서 유용하게 사용된다(Song, 2015). 군집분석으로 얻은 세분시장 유형 간 인구통계적 특성,

Table 1. Tourist motivations items used for the study (after Palacio, 1997)

\begin{tabular}{|c|c|c|c|}
\hline Escape & Healthy activity & Learn about nature & Cohesive \\
\hline $\begin{array}{l}\text { - For the Solitude } \\
\text { - My mind could move at a slower } \\
\text { pace } \\
\text { - Get away from other people } \\
\text { - Experience the tranquility }\end{array}$ & $\begin{array}{l}\text { - Help keep me in shape } \\
\text { - Improve my physical health } \\
\text { - Develop my skills and ability } \\
\text { - I could do something creative such } \\
\text { as photography } \\
\text { - I thought it would be a challenge }\end{array}$ & $\begin{array}{l}\text { - Be in a natural setting } \\
\text { - Observe the scenic beauty } \\
\text { - Enjoy the noise and smell of nature } \\
\text { - Understand the natural world better } \\
\text { - Learn more about nature } \\
\text { - The adventure }\end{array}$ & $\begin{array}{l}\text { - I could do things with my com- } \\
\text { panion } \\
\text { - I could be with friends } \\
\text { - To be with others who enjoy the } \\
\text { same }\end{array}$ \\
\hline
\end{tabular}

Table 2. Attitudes towards tourist responsible behavior items used for the study (modified after Kang and Moscardo, 2006)

\begin{tabular}{ll}
\hline & While I am travelling I try to \\
& - Learn about and understand the local culture \\
& $\cdot$ Meet local residents and learn about their way of life \\
& $\cdot$ Respect the local culture and customs \\
Before I travel I like to study or collect information & $\cdot$ Follow the social rules that apply at the places I visit \\
- About the natural environment of the destination & $\cdot$ Obey the nature conservation rules that apply at the places I visit \\
- About the lifestyle of the local residents & $\cdot$ Learn about and understand the environment \\
& $\cdot$ Participate in environmental education programmes \\
& $\cdot$ Not visit sites where the environment can be damaged \\
& $\cdot$ Use restaurants and accommodation run by local people \\
& $\cdot$ Make sure that some of the money I spend gœes into funds for nature conservation \\
& $\cdot$ Make sure that some of the money I spend goes into funds for the welfare of local residents \\
\hline
\end{tabular}


여행 특성, 만족도의 차이를 파악하기 위해 카이제곱분석 $\left(\chi^{2}\right)$ 과 일원배치분산분석(One-Way-ANOVA)을 실시하였다.

\section{IV. 분석결과}

\section{1. 표본의 인구통계적 특성}

표본의 인구통계적 특성을 살펴보면 남성 185 명 $(42.6 \%)$, 여 성 242명(55.8\%)으로 나타났으며, 연령은 15세 이상 및 20대가 58 명 $(13.4 \%), 30$ 대가 53명 $(12.2 \%), 40$ 대가 117 명 $(27.0 \%), 50$ 대가 156 명 $(35.9 \%), 60$ 대 이상이 50 명 $(11.5 \%)$ 이었다. 그 외 인 구통계적 특성은 Table 3 과 같다.

\section{2. 생태관광 동기 척도 탐색적 요인분석 및 신뢰도 분석}

생태관광 동기 문항의 측정변수는 척도 순화과정을 통하여 일부항목을 제거하였다. 먼저, 타당성을 검증하기 위하여 탐색 적 요인분석을 실시하였다. 모든 측정 변수는 구성요인을 추출 하기 위해서 주성분 분석(principle component analysis)을 사 용하였으며, 요인 적재치의 단순화를 위하여 프로멕스회전방식 (promax)을 채택하였다. 이 연구에서의 문항 선택기준은 고유 값(eigen value)은 1.0 이상, 요인적재치는 0.4 이상을 기준으로 하였다. 생태관광 동기는 선행연구와 동일하게 4 개의 요인으로 구분되었으며, 총 18 개 문항 중 12 개 문항이 이론 구조에 맞지 않게 적재되어 제거해 최종적으로 8 개 문항을 분석에 이용하였 다(Table 4 참조).

\section{3. 관광객 동기 및 태도 유형별 군집분석}

요인분석을 통하여 관광객들의 생태관광 동기를 4 가지로 분 류하고 생태관광 동기와 태도를 가지고 K-means 군집분석을 실시하여 3 개의 세부 집단으로 분류하였다. 분석 결과는 Table 5 에 제시된 것과 같다. 군집 1 은 114 명으로 구성되었으며, 주 로 높은 자연탐방 동기(4.14)와 생태관광 태도(4.06)를 보이는 유형의 집단으로 구분되어 '자연탐방형 책임 있는 관광객(이하 세분시장 1)'으로 명명하였다. 군집 2는 143 명으로 구성되었고, 군집 내에서는 가장 높으나 다른 군집에 비하여 낮은 수준의 자연탐방 동기(3.46)와 생태관광 태도(3.89)를 보이는 유형의 집단으로 분류되어 '소극적 자연탐방형 관광객(이하 세분시장 2)'으로 명명하였다. 마지막 군집 3 의 경우에는 177 명으로 구성 되었고, 높은 자연탐방 및 친목도모 동기(각각 $4.43,4.42$ )와 생태관광 태도(4.26)를 보이는 유형을 가진 집단으로 분류되어 '자연탐방/친목도모형 책임 있는 관광객(이하 세분시장 3 )'으

Table 3. Respondents' social demographic characteristics

\begin{tabular}{|c|c|c|c|c|c|c|c|}
\hline \multicolumn{2}{|r|}{ Division } & \multirow{2}{*}{$\begin{array}{c}\begin{array}{c}\text { Frequency } \\
(\mathrm{N})\end{array} \\
185\end{array}$} & \multirow{2}{*}{$\begin{array}{c}\text { Percentage } \\
(\%)\end{array}$} & \multicolumn{2}{|r|}{ Division } & \multirow{2}{*}{$\begin{array}{c}\text { Frequency } \\
(\mathrm{N})\end{array}$} & \multirow{2}{*}{$\begin{array}{c}\begin{array}{c}\text { Percentage } \\
(\%)\end{array} \\
9.9\end{array}$} \\
\hline \multirow{3}{*}{ Gender } & Male & & & \multirow{9}{*}{ Occupation } & Manager & & \\
\hline & Female & 242 & 55.8 & & Profession & 100 & 23.0 \\
\hline & Non-response & 7 & 1.6 & & Office worker & 47 & 10.8 \\
\hline \multirow{6}{*}{ Age } & 15 or more, 20 's & 58 & 13.4 & & Service industrial employee & 60 & 13.8 \\
\hline & 30 s & 53 & 12.2 & & Retired & 26 & 6.0 \\
\hline & 40 's & 117 & 27.0 & & Housewife & 68 & 15.7 \\
\hline & 50 's & 156 & 35.9 & & Student & 26 & 6.0 \\
\hline & $60^{\circ} \mathrm{s}$ or more & 50 & 11.5 & & Other & 55 & 12.7 \\
\hline & Non-response & 0 & 0.0 & & Non-response & 9 & 2.1 \\
\hline \multirow{3}{*}{$\begin{array}{l}\text { Marital } \\
\text { status }\end{array}$} & Single & 90 & 20.7 & \multirow{6}{*}{$\begin{array}{l}\text { Income level } \\
\text { (monthly) }\end{array}$} & Less than 2 million won & 62 & 14.3 \\
\hline & Married(divorced) & $336(12)$ & $77.4(2.8)$ & & Less than 4 million won & 161 & 37.1 \\
\hline & Non-response & 8 & 1.8 & & Less than 6 million won & 97 & 22.4 \\
\hline \multirow{3}{*}{$\begin{array}{c}\text { Residence } \\
\text { area }\end{array}$} & Seoul, Gyeonggi, Incheon & 402 & 92.6 & & Less than 8 million won & 41 & 9.4 \\
\hline & Others & 26 & 6.0 & & 8 million won or more & 55 & 12.7 \\
\hline & Non-response & 6 & 1.4 & & Non-response & 18 & 4.1 \\
\hline \multirow{4}{*}{$\begin{array}{c}\text { Education } \\
\text { level }\end{array}$} & High school graduate or less & 135 & 31.1 & & & & \\
\hline & College graduate & 240 & 55.3 & & & & \\
\hline & Master/Ph.D & 50 & 11.5 & & & & \\
\hline & Non-response & 9 & 2.1 & & & & \\
\hline
\end{tabular}


Table 4. Factor loadings for individual motivational items and Cronbach's a reliability coefficients for resulting scales

\begin{tabular}{|c|c|c|c|c|c|c|}
\hline \multirow{2}{*}{ Item } & \multicolumn{4}{|c|}{ Factor } & \multicolumn{2}{|c|}{ Reliability } \\
\hline & Learn about nature & Healthy activity & Escape & Cohesive & $a$ if item deleted & Cronbach's o \\
\hline Observe the scenic beauty & 0.84 & & & & 0.76 & \multirow{3}{*}{0.8} \\
\hline Enjoy the noise and smell of nature & 0.83 & & & & 0.71 & \\
\hline Be in natural setting & 0.82 & & & & 0.70 & \\
\hline I thought it would be a challenge & & 0.90 & & & 0.41 & \multirow{2}{*}{0.6} \\
\hline Help keep me in shape & & 0.56 & & & 0.17 & \\
\hline Get away from other people & & & 091 & & 0.34 & \multirow{2}{*}{0.5} \\
\hline For the solitude & & & 0.65 & & 0.11 & \\
\hline I could do things with my companion & & & & 0.84 & - & - \\
\hline Eigen-value & 2.39 & 1.44 & 1.28 & 1.01 & & \\
\hline Variance explanation power & 0.39 & 0.23 & 0.21 & 0.17 & & \\
\hline
\end{tabular}

Table 5. Mean scores for segments on extracted factors

\begin{tabular}{|c|c|c|c|c|c|}
\hline \multirow[b]{2}{*}{ Factors } & \multicolumn{3}{|c|}{ Cluster division } & \multirow[b]{2}{*}{$F$-ratio } & \multirow[b]{2}{*}{$p$-value } \\
\hline & $\begin{array}{l}\text { Cluster } 1 \text { nature seeking } \\
\text { responsible tourist }(\mathrm{n}=114)\end{array}$ & $\begin{array}{l}\text { Cluster } 2 \text { passive nature } \\
\text { seeking tourist }(\mathrm{n}=143)\end{array}$ & $\begin{array}{c}\text { Cluster } 3 \text { nature \& cohesion } \\
\text { seeking responsible tourist }(\mathrm{n}=177)\end{array}$ & & \\
\hline Learning about Nature & 4.14 & 3.46 & 4.43 & 21.64 & .000 \\
\hline Healthy Activity & 3.11 & 2.35 & 3.74 & 62.25 & .000 \\
\hline Escape & 2.86 & 1.88 & 3.10 & 12.48 & .000 \\
\hline Cohesive & 2.41 & 3.39 & 4.42 & 490 & .000 \\
\hline \multirow[t]{2}{*}{$\begin{array}{l}\text { Attitudes towards tourist } \\
\text { responsible behavior }\end{array}$} & 4.06 & 3.89 & 4.26 & 15.58 & .000 \\
\hline & $\begin{array}{l}\text { Nature seeking } \\
\text { responsible tourist }\end{array}$ & $\begin{array}{l}\text { Passive nature } \\
\text { seeking tourist }\end{array}$ & $\begin{array}{l}\text { Nature \& cohesion seeking } \\
\text { responsible tourist }\end{array}$ & & \\
\hline
\end{tabular}

로 명명하였다(Table 5 참조).

\section{4. 세분시장별 인구통계적 특성}

군집분석을 통해 도출된 3 개의 세분시장 간의 인구통계적 특성(성별, 연령, 결혼유무, 거주지역, 최종학력, 직업, 가구소 득)을 비교분석하기 위하여 교차분석을 실시하였다. 분석 결과
는 다음과 같이 나타났다(Table 6 참조). 세분시장 간 거주지 역, 최종학력, 직업, 가구소득은 통계적으로 유의미한 차이를 보이지 않았으나, 성별, 연령, 결혼유무는 통계적으로 유의미한 차이를 보였다. 세분시장 1과 3의 경우 여성 방문객 및 40 50 대의 비율이 높았으나, 세분시장 2의 경우 남성 방문객의 비율 이 높았으며, 다양한 연령대의 방문객이 분포하는 것으로 나타 났다. 또한, 세분시장 3 의 경우 다른 세분시장 대비 높은 기혼

Table 6. Respondent social demographic characteristics

\begin{tabular}{|c|c|c|c|c|c|c|}
\hline & Division & $\begin{array}{l}\text { Nature seeking responsible } \\
\text { tourist }(\mathrm{n}=114)(\%)\end{array}$ & $\begin{array}{l}\text { Passive nature seeking } \\
\text { tourist }(\mathrm{n}=143)(\%)\end{array}$ & $\begin{array}{l}\text { Nature \& cohesion } \\
\text { seeking responsible } \\
\text { tourist }(\mathrm{n}=177)(\%)\end{array}$ & Total $(\%)$ & $\begin{array}{c}\chi^{2} \\
(p \text {-value })\end{array}$ \\
\hline \multirow{2}{*}{ Gender } & Male & $48(25.9)$ & $73(39.5)$ & $64(34.6)$ & $185(100)$ & \multirow{2}{*}{$\begin{array}{c}7.326 \\
(0.026)\end{array}$} \\
\hline & Female & $66(27.3)$ & $67(27.7)$ & $109(45.0)$ & $242(100)$ & \\
\hline \multirow{5}{*}{ Age } & 15 or more, $20^{\prime} \mathrm{s}$ & $17(29.3)$ & $27(46.6)$ & $14(24.1)$ & $58(100)$ & \multirow{5}{*}{$\begin{array}{l}22.710 \\
(0.004)\end{array}$} \\
\hline & 30 's & $16(30.2)$ & $22(41.5)$ & $15(28.3)$ & $53(100)$ & \\
\hline & 40 's & $32(27.4)$ & $37(31.6)$ & $48(41.0)$ & $117(100)$ & \\
\hline & 50 's & $41(26.3)$ & $35(22.4)$ & $80(51.3)$ & $156(100)$ & \\
\hline & 60 s or more & $8(19.0)$ & $18(42.9)$ & $16(38.1)$ & $42(100)$ & \\
\hline
\end{tabular}


(Table 6. Continued)

\begin{tabular}{|c|c|c|c|c|c|c|}
\hline \multirow{2}{*}{$\begin{array}{l}\text { Marital } \\
\text { status }\end{array}$} & Single & $27(30.0)$ & $38(42.2)$ & $25(44.0)$ & $90(100)$ & \multirow{2}{*}{$\begin{array}{c}8.293 \\
(0.016)\end{array}$} \\
\hline & Married & $87(25.9)$ & $101(30.1)$ & $148(85.5)$ & $336(100)$ & \\
\hline \multirow{2}{*}{$\begin{array}{l}\text { Residential } \\
\text { area }\end{array}$} & Seoul, Gyeonggi, Incheon & $111(27.6)$ & $129(32.1)$ & $162(40,3)$ & 402(100) & \multirow{2}{*}{$\begin{array}{c}3.354 \\
(0.187)\end{array}$} \\
\hline & Others & $3(11.5)$ & $11(42.3)$ & $12(46.2)$ & $26(100)$ & \\
\hline \multirow{3}{*}{$\begin{array}{c}\text { Education } \\
\text { level }\end{array}$} & High school graduate or less & $34(25.2)$ & $40(29.6)$ & $61(45.2)$ & $135(100)$ & \multirow{3}{*}{$\begin{array}{c}2.026 \\
(0.722)\end{array}$} \\
\hline & College graduate & $63(26.2)$ & $84(35.0)$ & $93(38.8)$ & $240(100)$ & \\
\hline & Master/Ph.D & $15(30.0)$ & $16(32,0)$ & 19(38.0) & $50(100)$ & \\
\hline \multirow{8}{*}{ Occupation } & Manager & $12(27.9)$ & $16(37.2)$ & $15(34.9)$ & $43(100)$ & \multirow{8}{*}{$\begin{array}{r}4.408 \\
(0.918)\end{array}$} \\
\hline & Profession & $27(27.0)$ & $37(37.0)$ & $36(36.0)$ & $100(100)$ & \\
\hline & Office worker & $15(31.9)$ & $13(27.7)$ & 19(40.4) & $47(100)$ & \\
\hline & Service industrial employee & $14(23.3)$ & $16(26.7)$ & $30(50.0)$ & $60(100)$ & \\
\hline & Retired & $6(23.1)$ & $9(34.6)$ & $11(42.3)$ & $26(100)$ & \\
\hline & Housewife & $17(25.0)$ & $19(27.9)$ & $32(47.1)$ & $68(100)$ & \\
\hline & Student & $6(23.1)$ & $11(42.3)$ & $9(34.6)$ & $26(100)$ & \\
\hline & Other & $15(27.3)$ & $19(34.5)$ & $21(38.2)$ & $55(100)$ & \\
\hline \multirow{5}{*}{$\begin{array}{l}\text { Income level } \\
\text { (Monthly) }\end{array}$} & Less than 2 million won & $15(24.2)$ & $23(37.1)$ & $24(38.7)$ & $62(100)$ & \multirow{5}{*}{$\begin{array}{l}14.396 \\
(0.072)\end{array}$} \\
\hline & Less than 4 million won & $40(24.8)$ & $54(33.5)$ & $67(41.6)$ & $161(100)$ & \\
\hline & Less than 6 million won & $36(37.1)$ & $31(32.0)$ & $30(30.9)$ & $97(100)$ & \\
\hline & Less than 8 million won & $11(26.8)$ & $11(26.8)$ & $19(46.3)$ & $41(100)$ & \\
\hline & 8 million won or more & $8(14.5)$ & $16(29.1)$ & $31(56.4)$ & $55(100)$ & \\
\hline
\end{tabular}

자 방문율 $(86 \%)$ 을 보이는 차이점이 발견되었다.

\section{5. 세분시장별 여행 특성}

세분시장 간의 여행 특성(최근 3년간 대상지 방문횟수, 체류 시간, 동반자 유형, 동반자 수, 주요 교통수단, 대부 해솔1길에 서의 1 인 지출금액)을 비교분석하기 위하여 교차분석을 실시 하였다. 분석 결과는 다음과 같이 나타났다(Table 7 참조). 세 분시장 간 체류시간과 동반자 유형이 차이가 있는 것으로 나타
났는데, 모든 세분시장에서 당일방문객이 높은 비율을 차지하 나, 세분시장 2 의 경우 당일방문객 비율이 비교적 작은 것으로 나타났다. 동반자 유형의 경우 세분시장 1 은 가족/친척이, 세분 시장 2,3 은 친구/동료가 두드러지는 것으로 나타났다.

\section{6. 세분시장별 만족도}

세분시장 간의 여행 만족도(자연/문화 보전 만족도, 교통 만 족도, 지역주민 서비스 만족도, 편의시설 관리상태 만족도, 프

Table 7. Respondent travel characteristics

\begin{tabular}{|c|c|c|c|c|c|c|}
\hline & Sivision & $\begin{array}{l}\text { Nature seeking responsible } \\
\text { tourist }(\mathrm{n}=114)(\%)\end{array}$ & $\begin{array}{l}\text { Passive nature seeking } \\
\text { tourist }(\mathrm{n}=143)(\%)\end{array}$ & $\begin{array}{l}\text { Nature \& cohesion seeking } \\
\text { responsible tourist }(\mathrm{n}=177)(\%)\end{array}$ & Total $(\%)$ & $\begin{array}{c}\chi^{2} \\
(p \text {-value })\end{array}$ \\
\hline \multirow{2}{*}{$\begin{array}{l}\text { Revisit } \\
\text { in } 3 \text { years }\end{array}$} & First & $52(46.0)$ & $81(37.2)$ & $85(39.0)$ & $218(100)$ & \multirow{2}{*}{$\begin{array}{c}4.536 \\
(0.104)\end{array}$} \\
\hline & Revisit & $61(54.0)$ & $56(28.0)$ & $83(41.5)$ & $200(100)$ & \\
\hline \multirow{2}{*}{$\begin{array}{l}\text { Staying } \\
\text { time }\end{array}$} & One day & $101(27.8)$ & $109(30,0)$ & 153(42.1) & $363(100)$ & \multirow{2}{*}{$\begin{array}{c}0.015 \\
(0.015)\end{array}$} \\
\hline & Overnight & $13(18.8)$ & $33(47.8)$ & $23(33.3)$ & $69(100)$ & \\
\hline \multirow{5}{*}{$\begin{array}{l}\text { Type of } \\
\text { companion }\end{array}$} & Alone & $5(71.4)$ & $0(0.0)$ & $2(28.6)$ & $7(100)$ & \multirow{5}{*}{$\begin{array}{l}35.223 \\
(0.000)\end{array}$} \\
\hline & Couple & $11(29.7)$ & $16(43.2)$ & $10(27.0)$ & $37(100)$ & \\
\hline & Friends/collegues & $35(17.5)$ & $72(36.0)$ & $93(46.5)$ & $200(100)$ & \\
\hline & Family/relatives & $56(39.2)$ & $38(26.6)$ & $49(34.3)$ & $143(100)$ & \\
\hline & Group & $5(12.8)$ & $14(35.9)$ & $20(51.3)$ & $39(100)$ & \\
\hline \multirow{3}{*}{$\begin{array}{l}\text { Number of } \\
\text { companion }\end{array}$} & Less than 10 & $92(28.8)$ & $97(30.3)$ & $131(40.9)$ & $320(100)$ & \multirow{3}{*}{$\begin{array}{c}6.584 \\
(0.160)\end{array}$} \\
\hline & Less than 20 & $9(20.5)$ & $18(40.9)$ & $17(38.6)$ & $44(100)$ & \\
\hline & 20 or more & $11(16.4)$ & $27(40.3)$ & $29(43.3)$ & $67(100)$ & \\
\hline
\end{tabular}


(Table 7. Continued)

\begin{tabular}{|c|c|c|c|c|c|c|}
\hline \multirow{4}{*}{$\begin{array}{l}\text { Main } \\
\text { trasportation }\end{array}$} & Private/rent car & $98(27.2)$ & $117(32.5)$ & $145(40.3)$ & $360(100)$ & \multirow{4}{*}{$\begin{array}{c}5.272 \\
(0.509)\end{array}$} \\
\hline & City/intercity bus & $4(26.7)$ & $7(46.7)$ & $4(26.7)$ & $15(100)$ & \\
\hline & Chartered/tour bus & $9(18.4)$ & $15(30.6)$ & $25(51.0)$ & $49(100)$ & \\
\hline & Others & $3(42.9)$ & $2(28.6)$ & $2(28.6)$ & $7(100)$ & \\
\hline \multirow{6}{*}{$\begin{array}{c}\text { Expenditure } \\
\text { per person } \\
\text { per day }\end{array}$} & 0 won & $7(35.0)$ & $4(20.0)$ & $9(45.0)$ & $20(100)$ & \multirow{6}{*}{$\begin{array}{l}16.965 \\
(0.075)\end{array}$} \\
\hline & Less than 10,000 won & $22(27.2)$ & $21(25.9)$ & $38(46.9)$ & $81(100)$ & \\
\hline & Less than 30,000 won & $36(27.1)$ & $45(33.8)$ & $52(39.1)$ & $133(100)$ & \\
\hline & Less than 50,000 won & $30(26.5)$ & $30(36.5)$ & $53(46.9)$ & $113(100)$ & \\
\hline & Less than 100,000 won & $14(20.3)$ & $34(49.3)$ & $21(30.4)$ & $69(100)$ & \\
\hline & 100,000 won or more & $5(29.4)$ & $8(47.1)$ & $4(23.5)$ & $17(100)$ & \\
\hline
\end{tabular}

Table 8. Respondent satisfaction

\begin{tabular}{|c|c|c|c|c|c|}
\hline \multirow[t]{2}{*}{ Division } & $\begin{array}{l}\text { Nature seeking responsible } \\
\text { tourist }(\mathrm{n}=114)\end{array}$ & $\begin{array}{l}\text { Passive nature seeking } \\
\text { tourist }(\mathrm{n}=143)\end{array}$ & $\begin{array}{l}\text { Nature \& cohesion seeking } \\
\text { responsible tourist }(\mathrm{n}=177)\end{array}$ & \multirow[t]{2}{*}{$F$-ratio } & \multirow[t]{2}{*}{$p$-value } \\
\hline & Mean(S.D.) & Mean(S.D.) & Mean(S.D.) & & \\
\hline Conservation of nature and culture & $3.55(0.74)$ & $3.61(0.72)$ & $3.91(0.69)$ & 19.71 & 0.000 \\
\hline Transportations & $3.55(0.85)$ & $3.65(0.82)$ & $3.94(0.81)$ & 15.00 & 0.000 \\
\hline Local services & $3.26(0.68)$ & $3.35(0.62)$ & $3.42(0.74)$ & 3.624 & 0.058 \\
\hline Maintenance of facilities & $3.22(0.77)$ & $3.19(0.73)$ & $3.42(0.77)$ & 5.852 & 0.016 \\
\hline Programs & $3.17(0.64)$ & $3.15(0.66)$ & $3.34(0.75)$ & 4.921 & 0.027 \\
\hline Revisit intention & $3.76(0.79)$ & $3.59(0.82)$ & $3.99(0.79)$ & 7.985 & 0.005 \\
\hline Recommendation intention & $3.80(0.71)$ & $3.70(0.77)$ & $4.05(0.72)$ & 10.43 & 0.001 \\
\hline General satisfaction & $3.75(0.69)$ & $3.75(0.65)$ & $4.02(0.63)$ & 14.48 & 0.000 \\
\hline
\end{tabular}

로그램 만족도, 재방문 의향, 추천 의향, 전반적 만족도)를 비 교분석하기 위하여 일원배치분산분석(One-way ANOVA)을 실시하였다. 분석 결과는 다음과 같이 나타났다(Table 8 참조) 지역주민 서비스 만족도를 제외한 모든 만족도 항목에서 통계 적으로 유의미한 차이가 났으나, 항목별 만족도 평균이 대체로 3 4점 내외로 머무는 것으로 나타났다. 모든 세분시장이 프로
그램 만족도에서 가장 낮은 점수를 보였으며, 전반적인 만족도 는 세분시장 3 이 가장 높은 점수를 보이는 것으로 나타났다.

\section{V. 결과 고찰}

앞에서 비교 분석한 결과를 정리하면 Table 9와 같으며, 연

Table 9. Segment characteristics

\begin{tabular}{|c|c|c|c|}
\hline Division & $\begin{array}{l}\text { Nature seeking responsible tourist } \\
\qquad(\mathrm{n}=114)\end{array}$ & $\begin{array}{l}\text { Passive nature seeking tourist } \\
\qquad(\mathrm{n}=143)\end{array}$ & $\begin{array}{l}\text { Nature \& cohesion seeking } \\
\text { responsible tourist }(n=177)\end{array}$ \\
\hline Ecotourism motivation & Learning nature & $\begin{array}{l}\text { Passive (Compared to the other segments, } \\
\text { this segment has no outstanding moti- } \\
\text { vation while motivation of learning na- } \\
\text { ture is internally high.) }\end{array}$ & Learning nature / Cohesive \\
\hline $\begin{array}{l}\text { Attitudes towards tourist } \\
\text { responsible behavior }\end{array}$ & High & Medium & High \\
\hline $\begin{array}{l}\text { Social demographic } \\
\text { characteristics }\end{array}$ & $\begin{array}{c}\text { Female }(58 \%) \\
40^{\prime} \sim 50 \text { 's } \\
\text { Married }(76 \%)\end{array}$ & $\begin{array}{c}\text { Male }(52 \%) \\
20^{\prime} \sim 30^{\prime} \sim 40^{\prime} \sim 60^{\prime} \text { s } \\
\text { Married }(73 \%)\end{array}$ & $\begin{array}{c}\text { Female }(63 \%) \\
40^{\prime} \sim 50 \text { 's } \\
\text { Married }(86 \%)\end{array}$ \\
\hline Travel characteristics & $\begin{array}{c}\text { One day }(89 \%) \\
\text { Family/relatives }(50 \%)\end{array}$ & $\begin{array}{l}\text { One day }(77 \%) \\
\text { Friends/colleagues }(49 \%)\end{array}$ & $\begin{array}{l}\text { One day }(87 \%) \\
\text { Friends/colleagues }(53 \%)\end{array}$ \\
\hline Satisfaction & $\begin{array}{l}\text { General satisfaction is medium } \\
\text { Satisfaction in programs is the lowest }\end{array}$ & $\begin{array}{l}\text { General satisfaction is medium } \\
\text { Satisfaction in programs is the lowest }\end{array}$ & $\begin{array}{l}\text { General satisfaction is the highest } \\
\text { Satisfaction in programs is the lowest }\end{array}$ \\
\hline
\end{tabular}

\section{4 한국조경학회지 제 46권 3호(2018년 6월)}


구 결과를 고찰한 내용은 다음과 같다. 첫째, 생태관광 동기 중 '자연탐방'이 각 군집에서 가장 두드러지는 동기인 것으로 나타 났다. 비록 세분시장 2의 경우, 타 군집들에 비해 자연탐방 동 기가 소극적인 수준이었으나, 군집 내부에서는 가장 높은 수준 의 동기로 나타났다. 자연탐방 동기가 공통적으로 높게 나타나 는 점은 생태관광지를 비롯한 자연자원이 우수한 관광지를 방 문하는 관광객을 대상으로 하는 과거 실증연구들(Hultman et al., 2015; Kim and Baum, 2007; Palacio, 1997)의 결과와 맥락 을 같이 한다.

둘째, '자연탐방' 동기를 제외한 나머지 동기인 '일상탈출', '건 강증진', '친목도모'의 경우에는 세분시장에 따른 수준 차를 보 이는 것으로 나타났다. 세분시장 2 는 세분시장 1 과 3 에 비해서 전체적으로 소극적인 동기를 갖는 반면, 세분시장 3 은 세분시 장 1 과 2에 비해 강한 친목도모 동기를 갖는 것으로 나타났다. 이러한 결과는 생태관광 동기가 생태관광지를 방문하는 관광 객 시장을 세분화하는 기준으로 유용하다(Kamata and Misui, 2015)는 주장을 뒷받침하며, 생태관광지 경영자 및 마케터가 세분시장에 따른 효과적인 마케팅 전략을 세워야 할 필요성을 제기한다.

셋째, 세분시장에 따라 생태관광 태도에도 차이가 있는 것 으로 나타났다. 세분시장 3 은 가장 높은 생태관광 태도 수준을, 세분시장 2는 가장 낮은 생태관광 태도 수준을 갖는 것으로 나 타났다. 이와 같은 연구결과는 생태관광 태도가 생태관광 동기 와 함께 생태관광지를 방문하는 관광객 시장을 세분화하는 기 준으로 유용하다는 것을 의미한다. 또한 과거 연구들(Cvelbar et al., 2017; Formica and Uysal, 2001; Juvan and Dolnicar, 2014)이 관광객의 전반적인 환경관련 태도나 행동만을 측정하 여 시장세분화 가능성을 확인한 반면, 본 연구에 사용된 생태 관광 태도는 관광지에서 이루어지는 친환경적 행동뿐만 아니 라, 지역사회 및 주민에 대한 책임 있는 행동에 대한 태도를 측 정하고 있어 보다 포괄적인 기준으로 관광객 시장 세분화의 가 능성을 확인한데 의의가 있다.

넷째, 동기와 태도를 기준으로 세분화된 시장은 각각 인구통 계적 특성의 경우 성비와 연령, 그리고 결혼 유무 항목에서 통 계적으로 유의미한 차이를 보였으며, 여행 특성의 경우 체류시 간 및 동반자 유형 항목에서 통계적으로 유의미한 차이를 보였 다. 만족도의 경우, 지역주민 서비스 만족도 외 모든 항목에서 세분시장 간에 유의미한 차이가 있는 것으로 나타났다. 생태관 광지 경영자 및 마케터는 이러한 차이점에 근거하여 각 세분 시장을 대상으로 구체적이고 효과적인 방안을 마련할 수 있다. Dolnicar and Leisch(2008)가 제시한 것처럼 생태관광지 경영 자 및 마케터는 지속가능한 관광지 관리를 위한 효과적인 방법 으로 생태관광 태도 수준이 높은 세분시장 3 을 표적으로 하는 관광 마케팅 방안을 마련할 수 있다. 예를 들어 세분시장 3 의
경우, 다른 세분시장에 비해 여성 및 40 50대 방문객이 가장 많았으며, 주로 친구 및 동료와 함께 대상지에 방문하였고, 주 요 동기는 자연탐방과 친목도모였다. 또한, 다른 세분시장에 비 해 모든 만족도 항목에서 가장 높은 평균 점수를 보였다. 단, 해솔1길에서 제공하는 프로그램의 다양성 면에서는 비교적 낮 은 만족도를 보였다. 따라서 관광지에서의 친목도모 활동을 장려하는 다양한 프로그램을 개설하고, 이를 여성 및 40 50대 층에 집중적으로 홍보하며 재방문율을 높이는 방안을 마련할 수 있다.

다섯째, 한편 생태관광지 방문자는 자원이 제공하는 편익의 수혜자임과 동시에 관리 규칙을 준수할 의무를 가지므로 관광 지 내의 규칙 준수를 제고시키기 위한 보다 다양한 방법이 고 려될 수도 있다 $(\mathrm{Kim}, 2017 \mathrm{a})$. 특히 환경해설 및 교육과 같은 행동의사결정 인자의 조절은 방문자에게 관광지 이용방법이나 규칙을 설명해 줌으로써 스스로 부정적인 행동을 바꾸도록 유 도하는 의사소통 기법으로, 시행 비용과 방문자 만족의 관점에 서 바람직한 전략으로 사용될 수 있다 $(\mathrm{Kim}, 2017 \mathrm{a})$. 대부 해솔 1 길의 경우, 생태관광 태도가 비교적 낮은 세분시장 2를 대상 으로 행동 변화 유도를 위한 교육프로그램을 실시할 수 있는데, 이 세분시장의 경우, 15 세 이상 20대부터 50 대까지 다양한 연 령층이 분포함으로 이를 고려한 연령대별 교육프로그램 마련 이 필요하다.

\section{VI. 결론 및 제언}

이 연구는 우리나라 생태관광지를 방문하는 국내 관광객의 생태관광 동기와 태도를 조사 및 분석하여 관광객 그룹을 세분 화하고, 세분시장별 인구통계적 특성, 여행 특성, 만족도를 바 탕으로 생태관광지 마케팅 및 방문자 관리 전략 마련 방안을 제 시하고자 하였다. 또한, 학술적으로는 현재까지 국내에서 큰 관 심을 받지 못했던 생태관광지에 특화된 설문조사 및 분석 방 법론 개발에 기여하며, 생태관광 동기와 태도를 바탕으로 하는 시장세분화와 표적 마케팅의 가능성을 검토하고자 하였다. 이 를 위하여 생태관광협회와 경기관광공사 자문을 받아 대부 해 솔1길을 조사 대상지로 선정하고, 설문조사 및 분석을 실시하 였다. 구체적으로는 생태관광 동기와 생태관광 태도를 바탕으 로 응답자를 3 개의 세분시장으로 나누고, 각 세분시장 간 인구 통계적 특성, 여행 특성, 만족도 차이를 살펴보았다.

연구결과, 세 개의 세분시장은 공통적으로 '자연탐방' 동기가 두드러졌으나, 각기 다른 수준의 '일상탈출', '건강증진' '친목도 모' 동기를 갖는 것으로 드러났다. 또한, 생태관광태도 수준에 따라서도 서로 다른 세분시장이 통계적으로 유의미하게 분류 되었으며, 이렇게 분류된 각 세분시장 간의 인구통계적 특성, 여행 특성, 만족도도 다르게 나타나 이 연구에서 사용된 생태 
관광 동기와 태도 척도가 생태관광지 방문객 시장을 세분화하 는 기준으로 유용하다는 것을 확인하였다. 과거 연구들이 관광 객의 환경관련 태도만 측정하여 시장세분화 가능성을 확인한 반면, 이 연구는 지역사회 및 주민에 대한 책임 있는 행동에 대 한 태도의 측정과 분석을 포함하고 있다는 점에서 보다 포괄적 이고 생태관광지에 특화된 기준으로 시장 세분화의 가능성을 확인했다는데 의의가 있다.

또한 각 세분시장 간의 차이는 지속가능한 관광지 관리를 도 모하는 대상지 관리자로 하여금 생태관광 태도 수준이 높은 세 분시장 3 을 관광지로 유도하는 표적 마케팅을 가능하게 해준 다. 동시에 생태관광 태도가 비교적 낮은 세분시장 2 를 대상으 로 생태관광 태도 및 행동 변화 유도를 위한 교육프로그램을 실시하는 방안도 고려할 수 있게 해준다. 단, 이 연구는 겨울에 한정하여 조사가 이루어졌다는 한계점을 갖고 있다. 대상지를 방문하는 관광객들의 특성은 대상지 내 - 외의 여러 가지 상황 과 시간의 흐름에 따라 변한다. 따라서 지속적인 방문객 조사 를 실시하여 데이터베이스를 구축하고, 분석을 통한 변화 추이 를 살펴보는 것이 필요하다. 특히 계절에 따라 대상지의 자연 환경이 다를 뿐만 아니라 방문객의 구성과 행동이 다를 수 있 으므로, 추가 계절조사를 통한 자료의 세밀한 분석과 이해가 필요하다. 대상지 관리자는 일회성에 그치지 않는 데이터베이 스의 구축과 관리를 바탕으로 변화하는 관광객의 특성과 추이 를 정확히 파악하여 보다 세밀한 마케팅 및 방문자 관리 방안 을 마련할 수 있다.

주 1. 우리나라 만 15 세 이상의 국민들이 2016년 1월 1일부터 2016년 12월 31 일까지 실시한 국내 숙박 및 당일여행 일수의 총합계.

주 2. 자연환경보전법 제 2 조 18 항.

주 3. 2009년 한국문화관광연구원으로 수행기관이 변경되었음.

주 4. 경기관광공사와 한국생태관광협회의 자문과 도움을 받아 조사지로 선 정하였다.

주 5. 관광지식식정보시스템 (www.tour.go.kr)의 관광객 방문객 보고통계 참고.

\section{References}

1. Ajzen, I.(2005) Attitudes, Personality and Behavior, Open University Press. In: Maidenhead.

2. Cvelbar, L. K., B. Grün and S. Dolnicar(2017) Which hotel guest segments reuse towels? Selling sustainable tourism services through target marketing. Journal of Sustainable Tourism 25(7): 921-934.

3. Diamantopoulos, A., B. B. Schlegelmilch, R. R. Sinkovics and G. M. Bohlen(2003) Can socio-demographics still play a role in profiling green consumers? A review of the evidence and an empirical investigation. Journal of Business Research 56(6): 465-480.

4. Dolnicar, S. and F. Leisch(2008) Selective marketing for environmentally sustainable tourism. Tourism Management 29(4): 672-680.

5. Formica, S. and M. Uysal(2001) Segmentation of travelers based on environmental attitudes. Journal of Hospitality \& Leisure Marketing $9(3-4): 35-49$.

6. Hultman, M., A. Kazeminia and V. Ghasemi(2015) Intention to visit and willingness to pay premium for ecotourism: The impact of attitude, materialism, and motivation. Journal of Business Research 68(9): 1854-1861.

7. Juvan, E. and S. Dolnicar(2014) The attitude-behaviour gap in sustainable tourism. Annals of Tourism Research 48: 76-95.

8. Kamata, H. and Y. Misui(2015) The difference of Japanese spa tourists motivation in weekends and weekdays. Procedia-Social and Behavioral Sciences 175: 210-218.

9. Kang, M. H. and G. Moscardo(2006) Exploring cross-cultural differences in attitudes towards responsible tourist behaviour: A comparison of Korean, British and Australian tourists. Asia Pacific Journal of Tourism Research 11(4): 303-320.

10. Kang, M. H.(1999) Ecotourists' Travel Motivations and Attitudes in Korea: Scales Development and Comparative Analysis on Tourists Groups. Ph.D. Dissertation, Seoul National University. Korea.

11. Kang, M. H., N. J. Kim and S. D. Choi(2002) Identification of Ecotourists' Distinctive Characteristics by Comparing with Mass Tourists: Focusing on Travel Motivations and Attitudes.

12. Kim, L. C. J. and T. Baum(2007) Motivation factors of ecotourists in ecolodge accommodation: The push and pull factors. Asia Pacific Journal of Tourism Research 12(4): 349-364.

13. Kim, S. I.(2017a) Park Recreation. Seoul: Seoul National University Press.

14. Kim, S. I.(2017b) Ecotourism as future power engines. Naeil Shinmoon. Retrieved April 5, 2018, from https://www.naeil.com/news_view $/$ ?id_art $=233896$

15. Kim, S. I. and M. H. Kang(2002) Ecotourism. Seoul: Travel Analyst.

16. Kim, S. J.(2002) Study on Ecotourism Promotion Strategy. Seoul: Korea Culture and Tourism Institute.

17. Kollmuss, A. and J. Agyeman(2002) Mind the gap: Why do people act environmentally and what are the barriers to pro-environmental behavior? Environmental Education Research 8(3): 239-260.

18. Korea Culture and Tourism Institute(2015a) 2014 International Visitor Survey.

19. Korea Culture and Tourism Institute(2015b) 2014 Korea National Tourism Survey,

20. Korea Culture and Tourism Institute(2016) 2015 Korea National Tourism Survey.

21. Korea Culture and Tourism Institute(2017) 2016 Korea National Tourism Survey.

22. Korea Tourism Organization(2018) Foreign Tourist Statistics. Retrieved, April 27, 2018, from http://openapi.nsdi.go.kr/nsdi/eios/ OperationSumryDetail.do; jsessionid =EaHR7c00fOtfCAL T-Au5gW58. openapi11.

23. Kotler, P., J. T. Bowen, J. C. Makens and S. Baloglu(2006) Marketing for Hospitality and Tourism (Vol. 893): Prentice hall Upper Saddle River, NJ.

24. Matheson, C. M., R. Rimmer and R. Tinsley(2014) Spiritual attitudes and visitor motivations at the Beltane Fire Festival, Edinburgh. Tourism Management 44: 16-33.

25. Ministry of Environment(2014) Ecotourism Resident and Visitor Satisfaction questionnaire.

26. Northeast Michigan Council of Governments(2012) Ecotourism on the Sunrise Coast: A Marketing Report for Alpena, Aloona, \& Presque Isle Counties.

27. Oh, M. J. and S. Y. Lee(2008) Segmentation of ecotourist's motivation by traveler's types and satisfaction. International Journal of Tourism and Hospitality Research 22(1): 277-290.

28. Palacio, V.(1997) Identifying ecotourists in Belize through benefit segmentation: A preliminary analysis. Journal of Sustainable Tourism 
5(3): 234-243.

29. Park, H. Y. and H. J. Yang(2006) A study on the market segmentation of eco-tourism: Focused on eco-tourists of the Kanghwa tidal flat. Journal of Tourism Management Research 10(1): 137-159.

30. Park, J. Y., K. O. Hong and B. I. Seo(2010) Understanding of Tourist Behavior (3 ed.). Seoul: Namdu Doseo.

31. Queensland Government(2013) Queensland Ecotourism Plan 20132020.

32. Shouf Biosphere Reserve(2009) Shouf Biosphere Reserve Ecotourism Strategy.

33. Smith, W. R(1956) Product differentiation and market segmentation as alternative marketing strategies. Journal of Marketing 21(1): 3-8. 34. Song, J. J(2015) SPSS/AMOS Statistical Analysis (2 ed.). Paju: 21 Segisa.

35. The International Ecotourism Society(2006) The TIES Global Ecotourism Fact Sheet. In: International Ecotourism Society Washington, DC.

36. The International Ecotourism Society(2015) What is Ecotourism? Retrieved from http://www.ecotourism.org/what-is-ecotourism

37. UNEP and UNWTO(2012) Tourism in the Green Economy- Background Report. UNWTO, Madrid.

Received : 07 March, 2018

Revised : 05 April, 2018

28 May, 2018

Accepted : 28 May, 2018

(1st)

(2nd) 